\title{
“El Espacio Iberoamericano del Conocimiento en la perspectiva de transformación de la Universidad en una Microversidad"
}

\author{
"The Ibero-American Space of Knowledge from the perspective of \\ transformation of University into a Microversity" \\ "O espaço ibero-americano do conhecimento na perspectiva da \\ transformação da universidade em microversidade"
}

Recepción: 10/12/2018

Evaluación: 14/01/2019

Aceptación: 17/02/2019

Artículo de Investigación - Reflexión

https://doi.org/10.19053/01227238.9059

Justo Cuño Bonito ${ }^{1}$

Universidad Pablo de Olavide, España Grupo de investigación ILAC - UPTC 


\section{ABSTRACT}

Given the excessive attack of neoliberal policies on the structures that support the existence of public services in the national states, it emerges a generation of thought based on one's own, on diversity, on the cultural heterogeneity of Ibero-American societies. The present work analyzes the causes of the globalizing phenomenon and proposes as a solution the consolidation of the Ibero-American knowledge space as a tool for the construction of an alternative and transformative knowledge of our societies. We also aim to recover the universalist sense of the public University, which is intended to reduce into a simple microversity; oriented, ascribed, induced, and justified in the impoverishing process of relegating knowledge and enthroning of information.

Keywords: Ibero-American Knowledge Space; University; microversity; globalization; human capital; OEI; Ibero-American Summits; privatization; quality; UNESCO; OMC; OCDE; EEES; CEPAL.

\section{RESUMO}

Dado o excessivo ataque das políticas neoliberais sobre as estruturas que sustentam a existência de serviços públicos nos estados nacionais, impõe-se a geração de pensamento baseado na diversidade, na heterogeneidade cultural das sociedades ibero-americanas: Esta pesquisa analisa as causas do fenômeno globalizante e propõe como solução a consolidação do Espaço Ibero-americano de Conhecimento como ferramenta para a construção de um conhecimento alternativo e transformador de nossas sociedades. Também propomos recuperar o sentido universalista de uma universidade pública, que se pretende tornar uma simples "microversidade" orientada, atribuída, impulsionada e justificada no processo de empobrecimento de relegar o conhecimento e entronizar a informação.

Palavras-chave: Espaço Ibero-americano do Conhecimento; Universidade; microversidade; globalização; capital humano; OEI; Cúpulas Ibero-Americanas; privatização; qualidade UNESCO; MAC; OCDE; EHEA; CEPAL.

\section{INTRODUCCIÓN}

La investigación se articula a través del concepto microversidad, que pretende expresar el empequeñecimiento y empobrecimiento que las instituciones de educación superior han sufrido en las últimas décadas con relación a la irrupción de los modelos neoliberales en el contexto universitario. Efectivamente, la oferta educativa se ha empobrecido enormemente con la estructuración de unos planes de estudio vinculados directamente a los contextos económicos, prevaleciendo la razón de la "utilidad" entendida a partir de su significación en los diferentes sectores productivos y reasignando la labor formadora de las instituciones de educación superior, a partir de su formación de "capital humano".

La investigación analiza los principales nodos a partir de los cuales se produce este empobrecimiento, esta transformación de las instituciones universitarias en instituciones microversitarias al servicio del aparato productivo, despojadas de su conciencia crítica, a partir del estudio de tres aspectos fundamentales:

1. El nuevo modelo de relación del Estado y la Universidad pública: desfinanciación, creación de "capital humano", conceptos de gastos y servicios y eficiencia, calidad y competitividad y su consecuencia más evidente: el incremento de la oferta educativa privada en educación superior. 
2. La fuga de talentos y su impacto en el desarrollo futuro de los países más pobres.

3. La desinversión en educación pública y la relación entre desigualdad de la renta y desigualdad de capacidades, donde se demuestra que un modelo educativo más inequitativo y peor financiado, empobrece todo el tejido social, restringe el desarrollo de las capacidades y relega a la exclusión social a importantes sectores sociales.

Se analiza el origen y se valora como solución el proyecto de creación del Espacio Iberoamericano del Conocimiento (EIC) como una alternativa a este modelo imperante. El EIC debe surgir a partir de un profundo análisis de contexto que diversifique, a partir de un modelo común, el desarrollo educativo en el espacio iberoamericano.

Con respecto al estado del arte, indicaremos que la abundante literatura consultada sobre el tema, coincide en apreciar que desde los años 90, en un intento por alumbrar el resultado de las reformas estructurales en las economías latinoamericanas, se adoptó la consigna "menos Estado" intentando menoscabar las estructuras y funciones de unos Estados aún débiles (en lo social, en lo territorial e incluso en lo político). Un nuevo tiempo, una vieja era. Llegaba el momento de los nuevos paradigmas, que en realidad eran los viejos, los acuñados en el liberalismo más clásico, ese que surgía sin Estado, sin control, ajeno a la responsabilidad individual sobre las acciones singulares que repercutían colectivamente. El auge del individualismo es el fin de la universalidad y de la universidad: la globalización excluye el reconocimiento de sí en el otro, si no es a través del uso, del fin utilitarista convertido en medio. La ética de lo individual y la educación a su servicio, en un nuevo contexto histórico-sociopolítico-cultural ${ }^{2}$ donde lo crítico y lo humanístico queda devorado por lo técnico. Es el dominio de la lógica del mercado y de los seres humanos convertidos en capital social, capital cultural o capital humano, pero capital, al fin y al cabo: condicionados y acondicionados para someterse a las reglas del mercado, al uso y a la utilidad. Nunca fueron (ahora que están tan débiles) tan urgentes y tan necesarias las humanidades y nunca fue, ahora que empequeñeció tanto, tan necesaria la universalidad de la Universidad. Sin embargo, la universidad camina a quedar convertida en microversidad: constreñida y deslavazada su visión integradora del desarrollo humano a partir de todas las ciencias y de todas las artes, y marginada hasta convertirse en centro de la práctica funcional, del uso utilitarista del conocimiento en el tránsito del bien al servicio público.

No nos engañemos, ni nos dejemos engañar: el liberalismo y, su interpretación más reciente, el neoliberalismo, que viene a ser su reformulación más añeja, reniegan de la educación. La educación es vista como un gran negocio vinculado al mercado laboral, lo que, en sí, es un negocio doblemente perfecto: los indivi-

2 Diana Elvira Soto Arango, José Pascual Mora, José Rubens Lima Jardilino, "Formación de docentes y modelo pedagógico en la Universidad Pedagógica y Tecnológica de Colombia”, Revista Historia de la Educación Latinoamericana, vol. 19 no. 29 (2017): 35 - 66; José Molina Bravo. "Educación Pública, Autonomía Universitaria y Cambio Político: Notas para el Análisis Del Movimiento Universitario en Chile, 2011". Revista Historia de la Educación Latinoamericana vol.15 no. 21 (2014): 263-82. https://doi. org/10.19053/01227238.2473. 
duos pagan por la formación que beneficiará a los empresarios que diversifican sus intereses entre industrias y negocios educativos. De este modo, primero, obtienen ganancias a través de sus negocios educativos de aquellos estudiantes a los que cualifican para trabajar más tarde en industrias o servicios de los que ellos son también propietarios. Entre los 100 personajes más ricos de Colombia, se encuentran 4 dueños de universidades quienes a su vez son propietarios de constructoras, agencias inmobiliarias y centros de conciliación ${ }^{3}$. Algo similar a lo que ocurre en otros países iberoamericanos.

Que el informe CEPAL de 2018 nos anuncie que "el contrato social, entendido como un pacto tácito entre el Estado y los ciudadanos, está debilitándose en ALC debido a la insatisfacción con los servicios públicos y al deterioro de la percepción de bienestar", es cuanto menos, sorprendente. El texto de la CEPAL divaga y se contradice al exponer qué es un contrato social (tácito, implícito y explícito) que jamás existió, porque lo que hubo fue sencillamente una imposición violenta de las élites dominantes que fundaron Estados oligárquicos como espacios hegemónicos de dominación. Referirse a que la "caída de la confianza en las instituciones públicas y la creciente insatisfacción con los servicios públicos indica que los fundamentos del contrato social se han debilitado", es pecar de una ingenuidad pasmosa o de un profundo desconocimiento de la historia y de la realidad iberoamericanas. ${ }^{4}$

\section{Una nueva relación entre el Estado y la Universidad}

Efectivamente, las transformaciones económicas y el auge del neoliberalismo, retomaron con virulencia la doctrina del "laissez-faire, laissez-passer", puesta en práctica por unos Estados que no habiendo aún hecho lo suficiente para consolidar un mínimo Estado del bienestar, quisieron dejar el conjunto de la economía en manos privadas y retomar la configuración económico política de las repúblicas oligárquicas de finales del siglo XIX: se difundió la idea de que, si el Estado se involucraba menos y dejaba pasar más, el mercado y la sociedad desarrollarían una mejor gestión de los recursos y aplicarían iniciativas más novedosas y avanzadas. En este sentido, igualmente, el Estado debía reducir su presencia en la educación superior, generando nuevas fuentes de financiamiento, lo que se tradujo en un incremento del coste de matrícula asumido por los propios estudiantes y estableció nuevos vínculos entre la universidad y un mundo empresarial que obtuvo a través de la educación, convertida en un servicio, nuevas fuentes de financiación. Al mismo tiempo, el nuevo modelo propuso la reestructuración de los sistemas universitarios para reducir costos de funcionamiento y mejorar la eficiencia interna e implantar mecanismos de evaluación y acreditación que garantizasen una correcta gestión de todos los procesos. Y todo

3 El Observatorio de la Universidad Colombiana, Universidades "sin ánimo de lucro" ganaron 464.000 millones de pesos en 2009 (Ministerio de Educación de Colombia, 2011), en https://goo.gl//nWbJ9

4 OCDE/CAF/CEPAL Perspectivas económicas de América Latina 2018: Repensando las instituciones para el desarrollo, Éditions OCDE, (París: 2018), 27 
el replanteamiento del sistema se hacía a través de una visión uniformizadora y descontextualizada, sin los análisis previos requeridos sobre las características de cada sociedad y contexto para adaptar las soluciones a cada necesidad específica. Según el investigador Rodrigo Arocena, las instituciones internacionales propusieron el modelo educativo chileno como el modelo a imitar y "el Banco Mundial procuró convencer de que lo adoptaran como tal a casi todos los gobiernos latinoamericanos, y en muchos casos lo logró" (Arocena, 2004) 5 . Las instituciones públicas de educación superior se encontraron sin apoyos para enfrentarse al modelo neoliberal que se afanaba en necrosar todo el tejido universitario: los consejos directivos, a menudo, en connivencia con los gobiernos y las nuevas políticas universitarias; los docentes perdidos, ausentes, ajenos y los estudiantes extraños en una institución en la que no se encuentran representados por ser profundamente antidemocráticas, y que ni conocen, ni valoran, ni estiman: unos estudiantes que transitan por la institución como por el McDonalds. No en vano, en el año 2002, el director adjunto de UNESCO, John Daniel, propuso la aplicación del mismo modelo de la FAST FOOD, en las Universidades: una universidad inmediata, económica y previsible, rediseñando el modelo de Ray Kroc, pionero de la mundialización de McDonalds y quien en 1961 propuso la Universidad de la Hamburguesa y una especialización en hamburguesorología. ${ }^{6}$

ONU, UNESCO, el Banco Mundial, entre otros organismos supranacionales, idearon la nueva/vieja política en educación superior con el objetivo fundamental de vincular la formación superior al mundo empresarial, conectando de manera clara y precisa la formación y el conocimiento con el uso práctico, la formación del mercado laboral y el pernicioso uso de conceptos como "capital humano". Este concepto, autoasimilado y valorado positivamente por el propio mundo académico, convierte artificiosamente a los ciudadanos en propietarios, antes incluso que, en sujetos políticos, y los inserta en el sacrosanto mercado internacional como un producto más de intercambio. Nada nuevo, como decimos, todo rancio, viejo, manido, pero remozado para venderlo como novedoso. Yo soy propietario de mi propia persona dijo John Locke en sus "Tratados sobre el Gobierno Civil":

el gran y principal fin de que los hombres se unan en comunidades (commonwealths) y de que se sometan al gobierno es la preservación de su propiedad. El Estado es un instrumento garantizador del bienestar de los ciudadanos, de la paz civil, o sea, del libre gozo de sus bienes materiales: la propiedad no es asunto del Estado y por ello debe abstenerse por todos los medios posibles de intervenir en cuanto la afecte. Cuando el estado está instituido, lo que está instituido es una república de propietarios formada exclusivamente por propietarios y el poder que de ella emana, está ahí para mantener las propiedades privadas en el estado en que la naturaleza

5 Rodrigo Arocena, "Las reformas de la educación superior y los problemas del desarrollo en América Latina". Educ. Soc., Campinas, vol. 25, n. 88 (2004): 915-936.

6 Ana Isabel Poo del Castillo. "La empresa McDonald's: un elemento positivo en el proceso globalizador" (Tesis profesional, Licenciatura en Relaciones Internacionales. Universidad de las Américas, Puebla, 2006), cap. III, 15. 
las establece. No puede haber asociación para los no propietarios, aquellos que sólo se poseen a sí mismos: sólo los propietarios se asocian (... ).?

Ahora, incluso los no propietarios, también están inmersos dentro del mercado mundial: son consumidores, propietarios de su propia persona y como tal, poseedores de un intrínseco "capital humano". Albert Recio comentando la crítica de Bowles al capital humano ${ }^{8}$ señaló que la formulación del capital humano será un intento de eliminar cuestiones de clase. Las desigualdades son básicamente desigualdades de clase que determinan las inequidades en el acceso a la educación y, por tanto, la educación se convierte en un factor secundario en el proceso de favorecer la igualdad de oportunidades y movilidad social. Al respecto, indicará Bowles que:

a) Las estructuras de desigualdad están fundamentalmente fijadas por las estructuras productivas, $y$

b) El origen social juega un papel dominante a la hora de explicar las posibilidades de éxito educativo y de movilidad social.

Y ese fue el resultado: la hegemonía cultural de la élite busca establecer políticamente un consenso básico entre dominadores y dominados. Al tiempo, no solo asegura los medios de poder y producción, sino también la primacía sobre el mundo simbólico: controlar, según Gramsci, la reproducción de una ideología que explique y legitime las relaciones de poder existentes, al tiempo que proponga nuevas fórmulas que refrenden esta dominación. En este marco de dominación se inscriben conceptos, tan vinculados a la nueva microversidad como el indicado de "capital humano", pero también el de "eficiencia", "competitividad" o el de "calidad". 9 .

La calidad nos salvará. Es el nuevo hito de nuestro tiempo, el sacrosanto concepto que reconvierte lo malo en bueno y lo bueno en excelente. Pero ni sabemos qué es, ni para qué debe ser. Tampoco los modelos de calidad son regionales, ni integradores, ni adaptativos, sino únicos, exclusivos y excluyentes y nos los imponen como la panacea que gobierna las empresas privadas: modelos anglosajones creados por el ejército británico y perfeccionados por las empresas e instituciones estadounidenses.

El espacio del conocimiento ya es un espacio de mercado y este espacio es un espacio global que entra en contradicción con el abordaje de sus problemas y soluciones desde una óptica más próxima, aquella que algunos autores han caracterizado como "glonacal", pero cuya solución para los problemas planteados en muy raras ocasiones toma la perspectiva de lo local, regional o nacional. ${ }^{10}$

7 John Locke, Segundo Tratado sobre el Gobierno Civil: un ensayo acerca del verdadero origen, alcance y fin del gobierno civil, (Madrid: Tecnos, 2006), 43.

8 Albert Recio Andreu, "Educación y capitalismo en el análisis 'radical' de S. Bowles y H. Gintis". Revista de Economía Crítica, no18, segundo semestre (2014): 215-217.

9 Antonio Gramsci, La Política y el Estado Moderno (México: Premiá, 1978), 66.

10 José Joaquín Brunner (Coord.), Educación Superior en Iberoamérica. Informe 2016 (Santiago de Chile: RIL Editores, 2016$), 17$. 

de transformación de la Universidad en una Microversidad"

Para los modelos globales, la educación es un "gasto" y un "servicio". Sin embargo, muchos economistas analizan el "gasto" educativo como una inversión. El economista Manuel Salas de la Universidad de Granada afirmó recientemente que:

La inversión en educación universitaria siempre será rentable, no solo por los beneficios privados monetarios que confiere, sino también, y lo más importante, por unos beneficios privados no monetarios considerables: mayor salud, trabajos menos monótonos, mayor disfrute del ocio, amistades más influyentes, mentalidad más abierta, etcétera. ${ }^{11}$

\section{Tasas de empleo por nivel educativo alcanzado y grupo de edad (2014)}

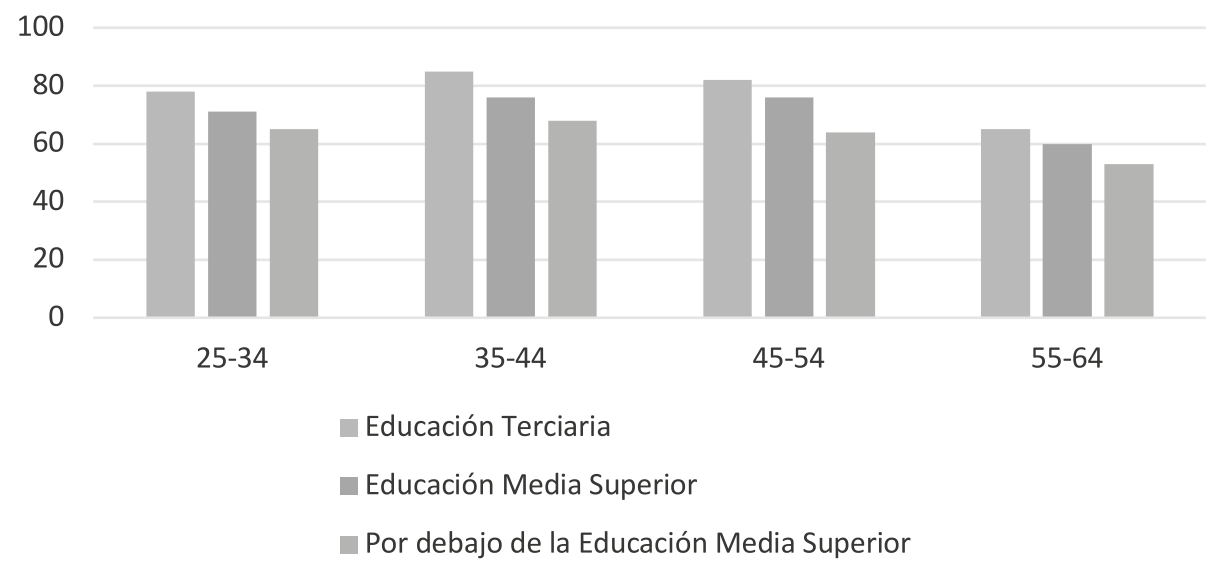

Ilustración 1. Tasas de empleo por nivel educativo alcanzado y grupo de edad (2014). Elaboración propia a partir de datos de la OCDE

En este mismo sentido, en el informe "Universidad, universitarios y productividad", se concluyó que, a mayor nivel de enseñanza completado, mayor rentabilidad de los años de estudio cursados. El rendimiento de la educación es mayor para los trabajadores con estudios universitarios: un 6,5\% en el caso de estudios de ciclo largo y un 5,9\% en los de ciclo corto. Un $4,2 \%$ en los estudios secundarios postobligatorios y un $1,6 \%$ para la educación secundaria obligatoria. ${ }^{12}$

11 Manuel Salas, "Invertir en Universidad, una apuesta rentable", El País, 1 julio 2013. En https://goo.gl/QPj9XB Consultado el 5 de marzo de 2017.

12 Francisco Pérez García y Lorenzo Serrano Martínez (Dirs.), Universidad, Universitarios y Productividad en España (Bilbao: Fundación BBVA, 2012), 274. 


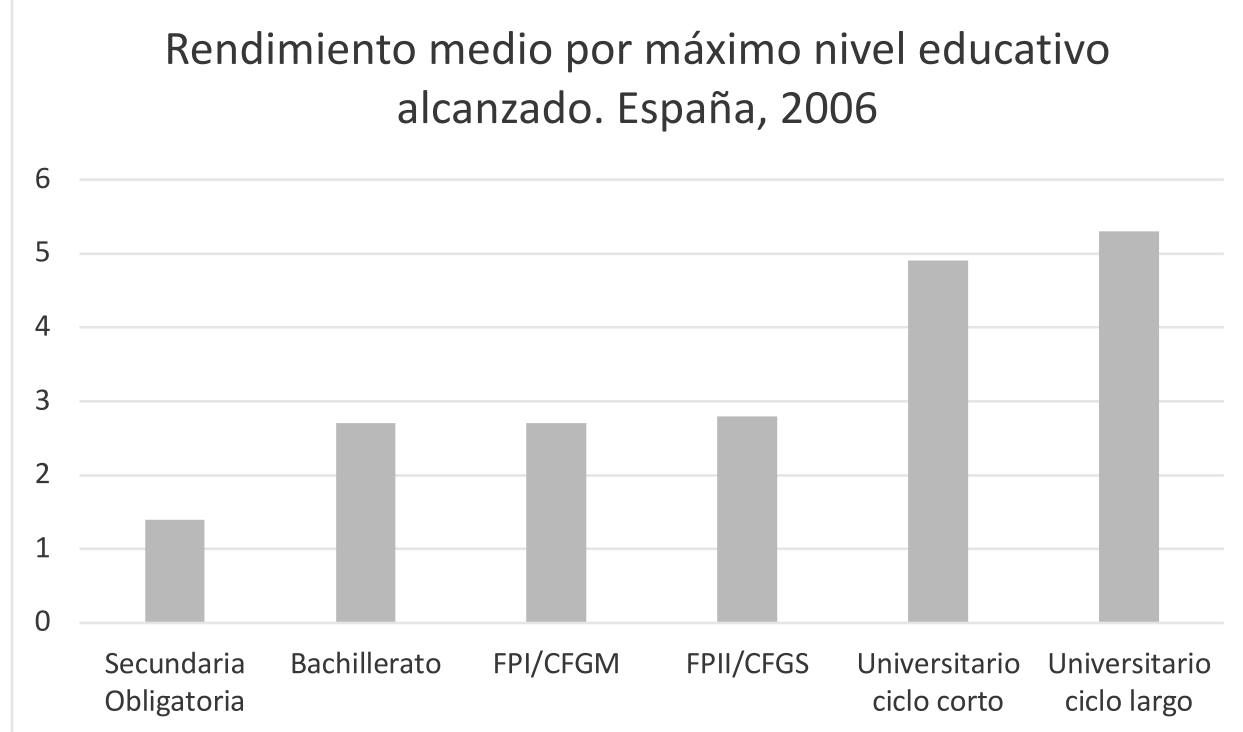

Ilustración 2. Rendimiento medio por máximo nivel educativo alcanzado. España, 2006. Elaboración propia a partir de datos de Pérez, F. y L. Serrano.

En un informe de los economistas Hanushek y Woessmann se concluyó que por cada 25 puntos de incremento en los resultados del informe PISA, una nación incrementa su Producto Interno Bruto un 3\%. Por tanto, la educación no es un gasto, sino una inversión: una mano de obra cualificada se asocia con tasas más altas de crecimiento económico. ${ }^{13}$

Dichas cifras justifican la inversión en educación, la inversión en investigación y la inversión en un modelo de educación superior verdaderamente democrático y autónomo, que elimine desigualdades en el acceso a la educación superior, fomente el desarrollo social de su entorno socioeconómico, y posibilite la permanencia y empleabilidad del talento. Sin embargo, la percepción es exactamente la contraria. Entre 2008 y 2015 la asignación de recursos públicos a las universidades españolas disminuyó un $20 \%$. El gasto por estudiante pasó de $7.760 €$ a $6.481 €$, una caída del $16,5 \%$, y las tasas universitarias se encarecieron entre un $20 \%$ y un $75 \%$ según las regiones. En ese mismo período, el número de estudiantes en las universidades españolas cayó a 127.000. A este panorama se añade la complejidad de las variaciones regionales: los centros vascos recibieron casi el doble de financiación pública por alumno que los madrileños, Andalucía gastó casi el cuádruple en relación al PIB que Islas Baleares y el precio de las tasas en Cataluña fue más del doble que el de las gallegas: 2.123 euros frente a $832^{14}$. Políticas disformes, gobiernos disformes y disformes ideologías, pero

13 OECD, Hanushek and Woessmann (2015), Universal Basic Skills: What Countries Stand to Gain, http://dx.doi. org/10.1787/9789264234833-en En OCDE. Fundación Santillana, Competencias en Iberoamérica: Análisis de PISA 2015 (Fundación Santillana, 2018), 37

14 Daniel Sánchez Caballero, Relato de una Universidad en crisis: menos financiación pública, más gasto privado y más lejos de Europa 
con el objetivo fundamental de docilizar a la universidad con el manejo de una financiación que, desestatalizándose, se intenta trasladar desde el Estado hacia las familias: en el último informe "La Universidad Española en Cifras" publicado por la Conferencia de Rectores se estimó que el coste medio de una primera matrícula es de 11,48€ por crédito, frente al gasto real de $115 €^{15}$. En un curso de $60 €$ el universitario pagaría un $10 \%$ del coste real: $689 €$ frente a $6.901 €$. Pero esta situación está siendo revertida, particularmente desde la ley Wert: en promedio, las universidades recibieron un $27,7 \%$ de fondos menos hoy que seis años atrás, pero lo compensaron con las subidas de las tasas: las universidades madrileñas recibieron un $33,7 \%$ menos de fondos y subieron un $40,7 \%$ sus tasas de matrícula; la Comunidad Valenciana un 35,3\% menos y subió sus tasas un 59,4\%.

Por ello, lejos de aminorar o erradicar las iniquidades sociales, las políticas en educación superior, en general, aplicaron unos presupuestos públicos que se mantuvieron estables o crecieron con moderación, pero que fueron los responsables de la disminución en la inversión por estudiante al tiempo que la matrícula creció exponencialmente. El escandaloso drenaje de recursos públicos, por parte de los gobiernos, con destino a los negocios educativos privados, tiene su caso más representativo en Colombia: el programa "Ser Pilo Paga" financió con recursos públicos, durante cuatro años, la matrícula de más de 40.000 jóvenes de bajos recursos que ingresaron en instituciones acreditadas como de alta calidad, mayoritariamente privadas (más del 70\%). El presupuesto en 2015, estimado en 155.000 millones de pesos colombianos, pasó a 374.000 en 2016, dinero público que se empleó para sobrefinanciar los elevadísimos costos de matrícula de esos negocios educativos privados. ${ }^{16} \mathrm{Y}$ no solo eso, además, las instituciones privadas aparecen en Colombia, al igual que en Chile, Guatemala o México, según un informe, desreguladas o dotadas de una regulación pública muy poco efectiva, frente a las regulaciones efectivas de Brasil, El Salvador o Perú ${ }^{17}$ Entregar dinero público a una institución privada que carece de una regulación efectiva es la mejor manera de perder todo el dinero público y entregarlo a los dueños de los negocios educativos privados.

En este contexto, no es extraño que estos negocios educativos privados crezcan exponencialmente. Mientras que en 1995 el número de universidades en América Latina era de 812, en 2003 alcanzó las 1.500 y más de la mitad ya eran privadas, profundizando con ello la brecha de la desigualdad. ${ }^{18}$ En un análisis

(eldiario.es, 2018), en https://goo.gl/TehVye

15 Juan Hernández Armenteros y José Antonio Pérez García, CRUE, Universidades Españolas, La Universidad Española en Cifras (Valencia: CRUE, 2017), 33.

16 Mara Constantinescu "La paradoja inclusiva. Efectos a corto y largo plazo de las políticas públicas para la educación superior en Colombia” (tesis de Máster en Latin American Studies, Leiden University, julio, 2018), 43.

17 José Joaquín Brunner (Coord.). Educación Superior en Iberoamérica. Informe 2016, (Santiago de Chile: Centro Interuniversitario de Desarrollo (CINDA), 2016), 194.

18 Norberto Fernández Lamarra. "Hacia la convergencia de los sistemas de educación superior en América Latina" Revista Iberoamericana de Educación, no. 34 (2004): 39-71. 
de la investigadora García Guadilla en 2008 se contabilizó un total de 1.423 universidades de las cuales, 432 eran públicas y 991, privadas $^{19}$.

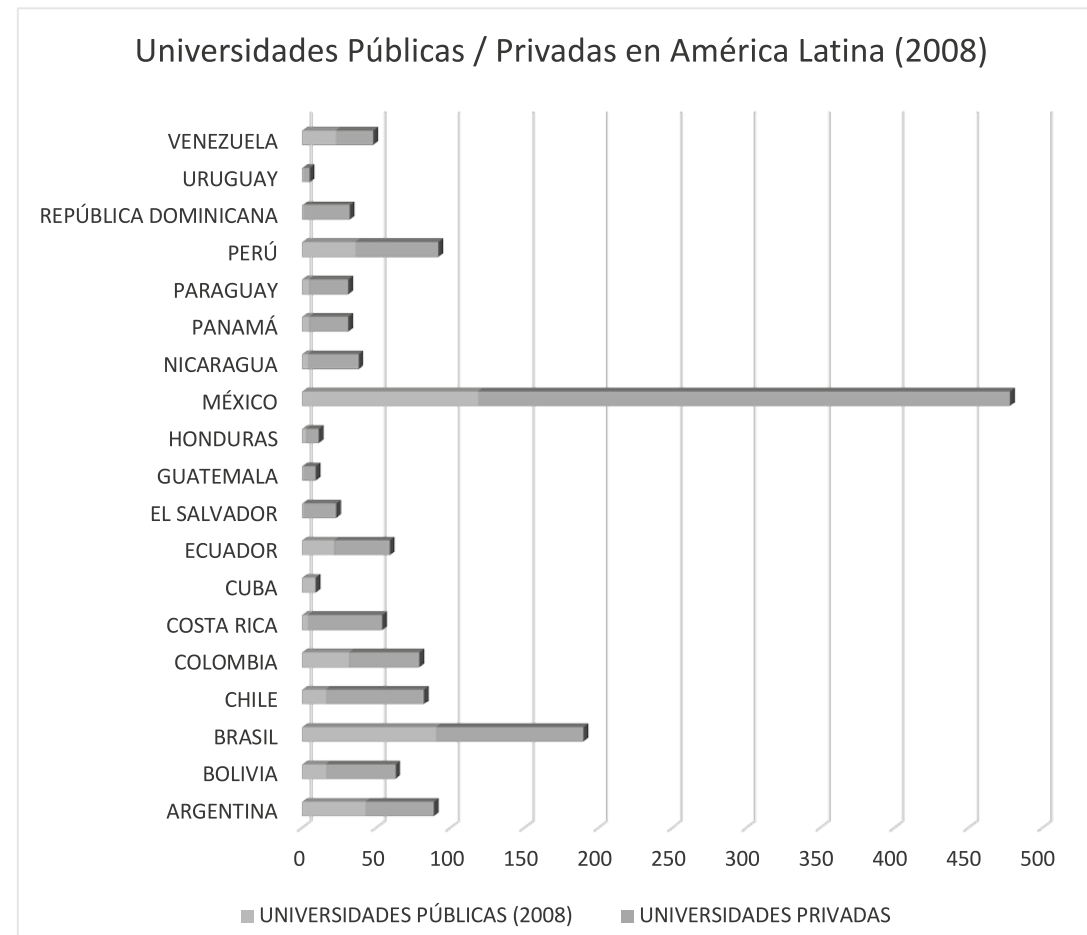

Ilustración 3. Relación entre Universidades Públicas y Privadas en América Latina en 2008. Elaboración propia a partir de los datos de Carmen García Guadilla. En https://goo. $g l / 4 q E q v u$

Numerosos informes han destacado el avance imparable de la privatización de la enseñanza superior, convertida en un objeto más de mercadeo. En recientes estudios de México y Brasil ya se contabilizan 5.832 instituciones de educación privada, frente a las 1.691 públicas (29\%). 21\% de los estudiantes argentinos, $46,5 \%$ de los colombianos y $73.4 \%$ de los chilenos se matricularon en 2012 en una institución privada. En la mayor parte de estas instituciones solamente se lleva a cabo el ejercicio docente, se realiza muy poca investigación y no cuentan con casi ninguna extensión universitaria. En Ecuador, tras la evaluación en 2012 por parte del Consejo de Evaluación, acreditación y aseguramiento de la calidad (CEACES) se procedió al cierre de 22 universidades, todas privadas. Las universidades de garaje (en Colombia) o de patio (en México) continúan con sus negocios sin que ningún ente de acreditación de la calidad las someta a un examen minucioso ${ }^{20}$.

19 Carmen García Guadilla. "Lista de Universidades de América Latina desde su fundación”. En https://goo.gl/1sTc57

20 Roberto Escalante Semerena. "Lo público y lo privado en la educación superior en América Latina". En https://goo.gl/xkXCcJ 


\section{Los organismos multinacionales y su consideración de la educación como "un servicio comercial": a la caza del talento}

En consecuencia, el caldo de cultivo, afanosamente preparado por los organismos internacionales, dio sus frutos: como indicábamos, el Banco Mundial en los años noventa y la OCDE en el nuevo siglo, impulsaron decididamente la consideración de la educación como un servicio más, promoviendo, vigilando y controlando, que los países de la organización disminuyeran su gasto público y abrieran el espacio de la educación superior a la iniciativa privada. Recordemos que el Acuerdo General sobre Comercio de Servicios (AGS) de 1995, ideado por la Organización Mundial del Comercio (OMC), acabó considerando la educación superior como un servicio comercial, frente a la visión de la educación como un "bien público". UNESCO, aparentemente, guardó distancias con esta política, aunque en la Conferencia Mundial de 2009 un grupo significativo de UNESCO defendió las posiciones de la OCDE, desconociendo, o queriendo desconocer, que la economía de mercado perjudica la posición de la universidad como bien público al servicio de la sociedad. ${ }^{21}$

Es en este proceso planificado por la $\mathrm{OMC}$, donde se inscribe la internacionalización de la educación superior; proceso en el cual, Bolonia 1998 (y declaraciones subsiguientes) constituyeron una guía fundamental para delinear los objetivos de la política universitaria en Iberoamérica. Aunque Bolonia no pretendió ultrapasar las fronteras del Espacio Europeo de Educación Superior (EEES), la idea del incremento de bienestar de la sociedad europea y de la competitividad del sistema de educación superior se convirtieron en una máxima que los gobiernos latinoamericanos quisieron desarrollar en sus propios territorios. Los grandes conceptos asociados a Bolonia, sonaban bien: desarrollo socioeconómico, paz y democracia, cooperación, el concepto de calidad, la naturaleza, los derechos humanos, la educación necesaria para el bienestar de la humanidad, la democracia, la solidaridad, la miseria y pobreza regional. Grandes conceptos, vacíos de contenido en su formulación, pero que fueron adoptados (que no adaptados) a los contextos latinoamericanos. El comunicado de Berlín de 2003 fue el encargado de entronizar el concepto de calidad y de vincular conocimiento y mercado laboral colocando dicho conocimiento al servicio de la competitividad del mercado europeo. Para ello la guía, a su vez, del Espacio de Educación Superior Europeo (EEES), era el espacio de educación superior de Estados Unidos y el ejemplo vivo que daba ese país en el proceso de vincular conocimiento y mercado laboral..$^{22}$ Los mecanismos puestos en marcha para atraer el talento foráneo, también fueron copiados por los gobiernos europeos en el proceso de internacionalización de la educación superior. Adviértase que mientras el espacio Schengen (1995) abría las fronteras internas, también reforzaba las exter-

21 Diana Elvira Soto Arango, Araceli Forero Romero, "La Universidad Latinoamericana y del Caribe en los desafíos del siglo XIX", Revista Historia de la Educación Latinoamericana, vol.18 no. 26 (2016): 279-309.

22 Comunicado de Berlín. Conferencia Europea de Ministros de Educación Superior (Berlín:2003). En http://www.eees.es/pdf/Berlin_ ES.pdf 
nas, en un proceso en el que paralelamente a partir de la declaración de Berlín, el EEES abría sus fronteras al talento imitando el proceso iniciado por Estados Unidos décadas antes. "Open Doors (2014)" un reciente estudio del Institute of International Education, se mostró que los estudiantes extranjeros dejaron importantes dividendos en la economía de los Estados Unidos, pasando de nueve a veintisiete billones de dólares en un lapso de quince años; un ejemplo fue el de los doscientos trece millones de dólares que invirtieron siete mil ochenta y tres estudiantes colombianos movilizados a ese país. Además, según un estudio de la National Foundation for American Policy el 50\% de los unicornios del país, es decir, las empresas valoradas en más de 1.000 millones de dólares, cuentan con al menos un inmigrante entre sus fundadores: el $42 \%$ de la plantilla de Twitter es extranjera mientras que en Facebook ese porcentaje es de un 28,6\%; para Google 28,28\%, Intel cuenta con un 20,3\% y Apple con un 10,4\%. De acuerdo con un informe elaborado por el Departamento de Seguridad Nacional de Estados Unidos (DHS, por sus siglas en inglés) en mayo de este año había en ese país 1.379.370 estudiantes extranjeros, de los cuales 194.635 pertenecen a programas de intercambio. China encabeza la lista con amplia diferencia con aproximadamente 325.000 alumnos, de los cuales alrededor de 130.000 cursan estudios de licenciatura y más de 100.000 realizan maestrías. El número total de estudiantes procedentes de América Latina es de 79.522, de los cuales 58.875 están matriculados en programas de educación superior. En su reporte, el DHS destaca que entre mayo de 2016 y mayo de 2017 fueron los alumnos de América del Sur los que más aumentaron en número en Estados Unidos: 6,5\%." ${ }^{23}$

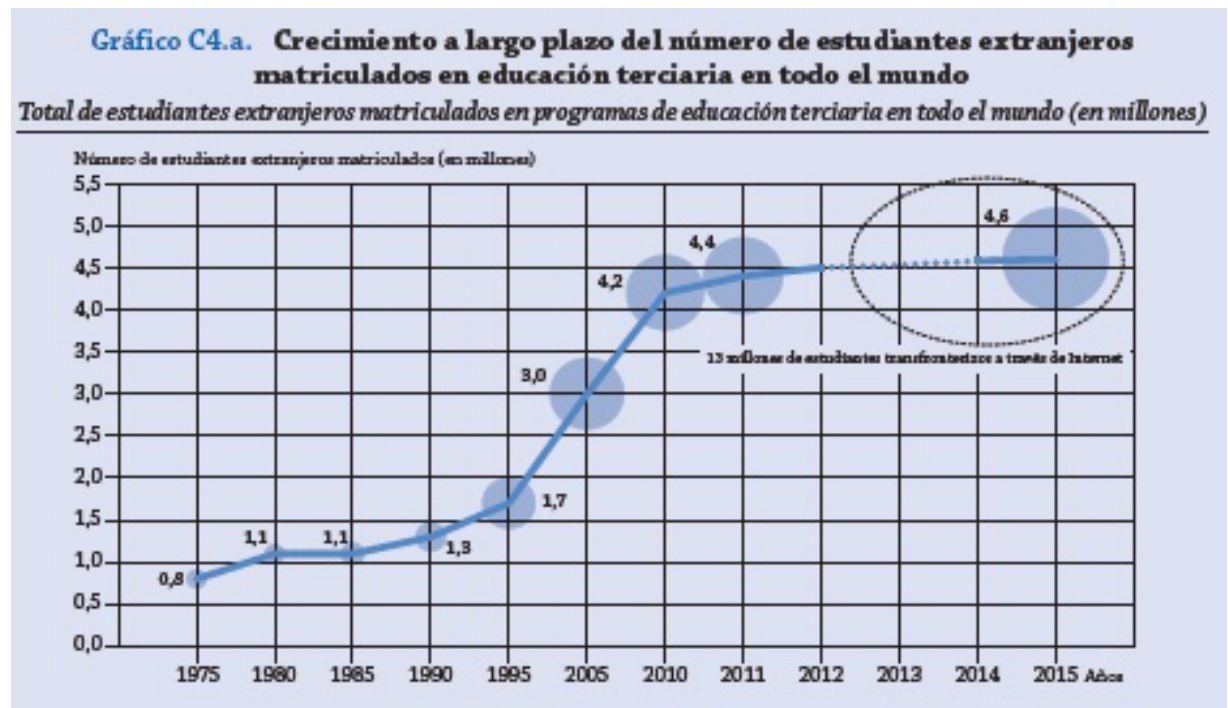

Ilustración 4. Fuente: OCDE. Panorama de la Educación 2017

23 El Confidencial. Trump incendia Silicon Valley: su plan antiinmigración afecta al 20\% de empleados. En https://goo.g1/UPLGUk 
La educación superior se ha convertido en un enorme negocio a nivel internacional: según cifras de la OCDE y UNESCO, los estudiantes que estudian en un país extranjero aumentaron de 1.7 millones en 1995 a 4.5 millones en 2012 $\mathrm{y}$ aunque en los últimos años la tendencia se ha estancado, el volumen sigue sorprendiendo por su magnitud. ${ }^{24}$ En este sentido de atraer el talento foráneo, se orientó el Comunicado de Bergen de 2005, que mostró el objetivo de convertir el Espacio de Educación Superior Europeo en un foco atracción de talentos foráneos basándose (eso sí), en el entendimiento y respeto intercultural. ${ }^{25}$ UNES$\mathrm{CO}$ ha emitido comunicados en contra de las prácticas asociadas a la "fuga de cerebros". En uno de ellos, destacó el peligro que ese fenómeno implica para el desarrollo futuro de los países pobres ${ }^{26}$, algo remarcado en varios trabajos que subrayaron la necesidad de contener en América Latina la fuga de talentos y la emigración de personal cualificado, convirtiendo la pérdida definitiva en una oportunidad que abra la globalización ${ }^{27}$. La Cumbre Iberoamericana de Jefes y Jefas de Estado y de Gobierno incidió en 2014 en Veracruz, en ese mismo asunto ${ }^{28}$ y en la Conferencia Regional de Educación de este mismo 2018, se calificó como de "difícilmente superables" los daños sufridos por las universidades públicas debido al efecto "devastador" de la "fuga de talento". ${ }^{29}$

\title{
3. Desigualdad en la renta y desigualdad en las capacidades
}

Con el nuevo milenio la matriculación en educación superior ha continuado creciendo en los ámbitos público y privado, y si bien ha crecido el número de universidades, los procesos de acreditación y evaluación han contenido dicho aumento.

Todo ello, sin embargo, ha evolucionado en un contexto de una gran desigualdad. Para el director de CLACSO, Pablo Gentili,

\begin{abstract}
América Latina tiene un arrastre de exclusión, un acumulado de discriminación en el ámbito educativo, que es inmenso. Pasaron casi cien años de la reforma universitaria que comenzó en Córdoba y que pensó un modelo universitario más inclusivo, más democrático, como un espacio de socialización del poder para las clases populares, pero aún hoy sigue habiendo una enorme exclusión de los más pobres en las instituciones de educación superior.
\end{abstract}

24 Dirk Van Damme. El crecimiento de la movilidad estudiantil internacional está decayendo. International Higher Education no. 93 (2018): 13-14.

25 Comunicado de Bergen. Conferencia Europea de Ministros de Educación Superior (Berlín:2005). En https://goo.gl/WhMncM

26 UNESCO destaca escasez de ingenieros como amenaza al desarrollo (2010). En https://goo.gl/aG89wk

27 Sylvie Didou Aupetit, Gérard Etienne. Fuga de cerebros, movilidad académica, redes científicas, (México: Centro de Investigaciones y de Estudios Avanzados del Instituto Politécnico Nacional, 2009), 8.

28 XXIV Cumbre Iberoamericana de Jefes de Estado y de Gobierno. Declaración de Veracruz. En https://goo.gl/SkSVaR

29 Orlando Albornoz. "La empleabilidad: las universidades, los profesionales universitarios y el comportamiento del mercado laboral", en El papel estratégico de la educación superior en el desarrollo sostenible de América Latina y El Caribe, Coord. Pedro Henríquez Guajardo (Córdoba, Argentina: UNESCO-IESALC y UNC, 2018), 134; Justo Cuño Bonito. Reforma Y Contrarreforma de la Enseñanza Primaria durante la II República Española y el Ascenso Del Fascismo (1932-1943). Revista Historia de la Educación Latinoamericana vol. 15 no. 21 (2014): 89-106. https://doi.org/10.19053/01227238.2468. 
De igual manera ha reflexionado Hugo Aboites, rector de la Universidad Autónoma de la Ciudad de México para quien la desigualdad educativa responde a problemas sociales de fondo y que, al igual que "la inequitativa distribución del ingreso, las condiciones de marginación, subordinación y exclusión de las mujeres y de los pueblos originarios", tiene "un impacto directísimo en las posibilidades de grandes sectores de la población de ingresar, permanecer y concluir los distintos niveles educativos". Aboites destacó los problemas "relacionados directamente con el sistema mismo de educación superior", entre ellos, "la falta de políticas de gratuidad y de apoyo económico (becas) a quienes tienen mayores necesidades, el uso de exámenes de selección y la rigidez del diseño académico que dificulta el acceso y permanencia de aquellos que trabajan o tienen otras ocupaciones". Algo que es particularmente grave en algunos de los países más desarrollados de la región, como en Chile, Brasil y Colombia. ${ }^{30}$

Es necesario insistir en la existencia una relación directa entre educación y desarrollo. En la mayor parte de las naciones más desarrolladas, la educación superior es pública, aunque no necesariamente sea completamente gratuita. En Dinamarca el 98\% de los estudiantes de educación superior estudian en instituciones públicas, el $92 \%$ de los australianos, el $81 \%$ de los finlandeses e incluso el $73 \%$ de los estudiantes de Estados Unidos. En este mismo sentido, la CEPAL en un reciente informe ${ }^{31}$ ha vinculado directamente educación superior y las posibilidades de conseguir un trabajo digno, y ha destacado en su informe que "la reciente expansión de la cobertura educativa debe ir acompañada de vínculos más fuertes con el mercado laboral. Pese a los notables progresos en educación durante la última década, menos de un tercio de los jóvenes latinoamericanos de entre 25 y 29 años ha recibido algo de educación superior en colegios universitarios, universidades o institutos técnicos de nivel superior". El informe del Centro Interuniversitario de Desarrollo, CINDA, elaborado en 2016 concluyó que las personas con mayor nivel educativo tienen mejores probabilidades de empleo que las personas con un bajo nivel. Las de nivel superior, representaron anualmente un promedio de desempleo de un 18\% del desempleo total (Brunner, 2016) ${ }^{32}$.

30 Pablo Gentili, "Desigualdad e inclusión en las universidades latinoamericanas". En Contrapuntos, Diario El País, 31/07/2016 https:// goo.gl/VGYucB

31 OCDE/CEPAL/CAF. Perspectivas económicas de América Latina 2017: Juventud, competencias y emprendimiento, OECD Publishing, París: (2016), http://dx.doi.org/10.1787/leo-2017-es

32 José Joaquín Brunner, (Coord.). Educación Superior en Iberoamérica. Informe 2016 (Santiago de Chile: Centro Interuniversitario de Desarrollo (CINDA), 2016), 159. 


\section{Gasto público en educación, total (\% del gasto del gobierno)}

35

30

25

20

15

10

5

0

20002001200220032004200520062007200820092010201120122013201420152016

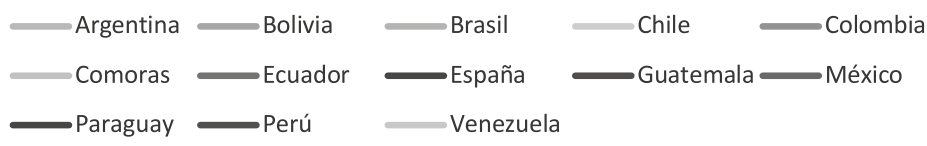

Ilustración 5. Gasto público en educación, total (\% del gasto del gobierno). Elaboración propia a partir de datos del Banco Mundial.

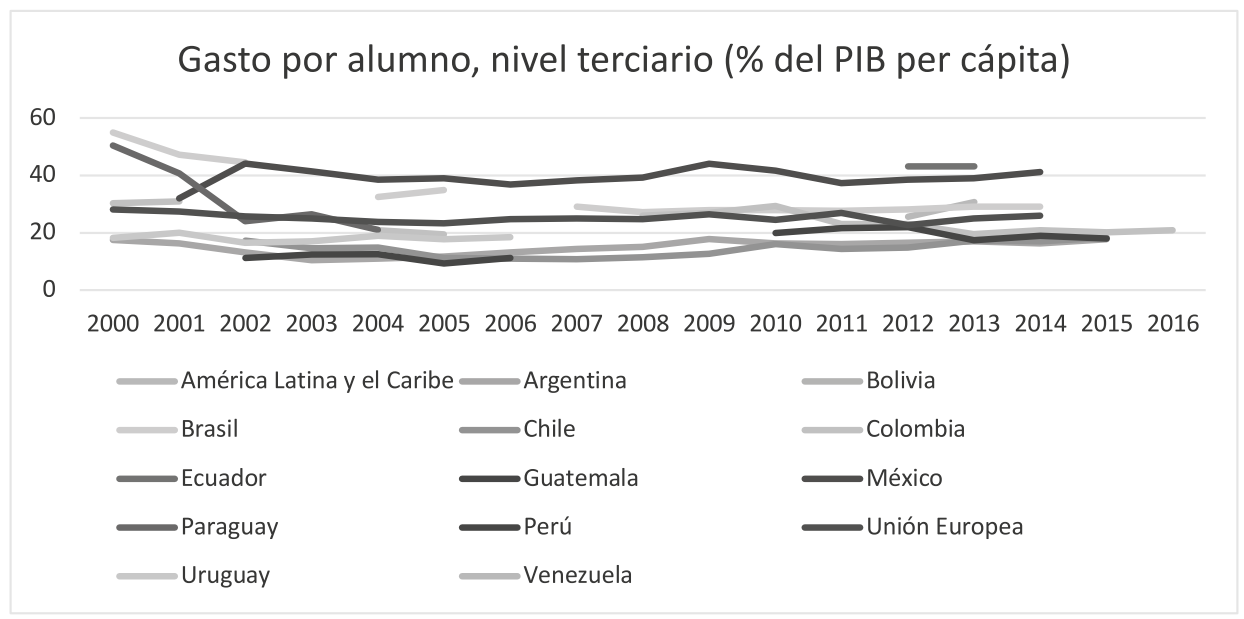

Ilustración 6. Gasto por alumno, nivel terciario (\% del PIB per cápita). Elaboración propia a partir de datos del Banco Mundial.

Sin embargo, los procesos de desinversión del Estado en educación no han hecho sino crecer. La desinversión en educación pública es la nota predominante si analizamos la perspectiva de evolución de la Universidad en América Latina en estos últimos años. Los argumentos siempre son los mismos y sirven tanto 
para justificar la desinversión en lo público, como para justificar la inversión de lo público en lo privado:

1. Es necesario aumentar la eficiencia: lo privado, por ser privado es más eficiente. Pero no hay argumentos que corroboren esta afirmación. Recordemos que, tanto en América Latina como en Europa y Estados Unidos, el rescate ante la quiebra de los sistemas bancarios privados se ha realizado con dinero público.

2. Es necesario tener libertad para elegir: se privatizan los servicios públicos para priorizar la competencia y ofrecer al consumidor más opciones que al final acaban transformándose en monopolios $\mathrm{u}$ oligopolios privados. Sí, podemos elegir entre Microsoft y Apple, Pepsi y Coca Cola, McDonalds y Burguer King, Visa y Mastercard, Adidas y Nike, Intel y AMD.

3. Es necesario frenar el abuso que los usuarios hacen de los servicios públicos: los usuarios abusuarios.

4. Los servicios públicos tienen un coste muy alto, por lo que la privatización es la única salida.

5. Los fondos públicos son exiguos y no hay suficientes para financiar los servicios sociales. Y es cierto, los fondos públicos existentes tras el rescate de empresas privadas son cada vez más escasos. Pero esto no está relacionado con la cantidad de fondos, sino con el destino y prioridades que se les da a estos fondos públicos.

Gráfico B3.1. Proporción de gasto privado en instituciones educativas (2014)

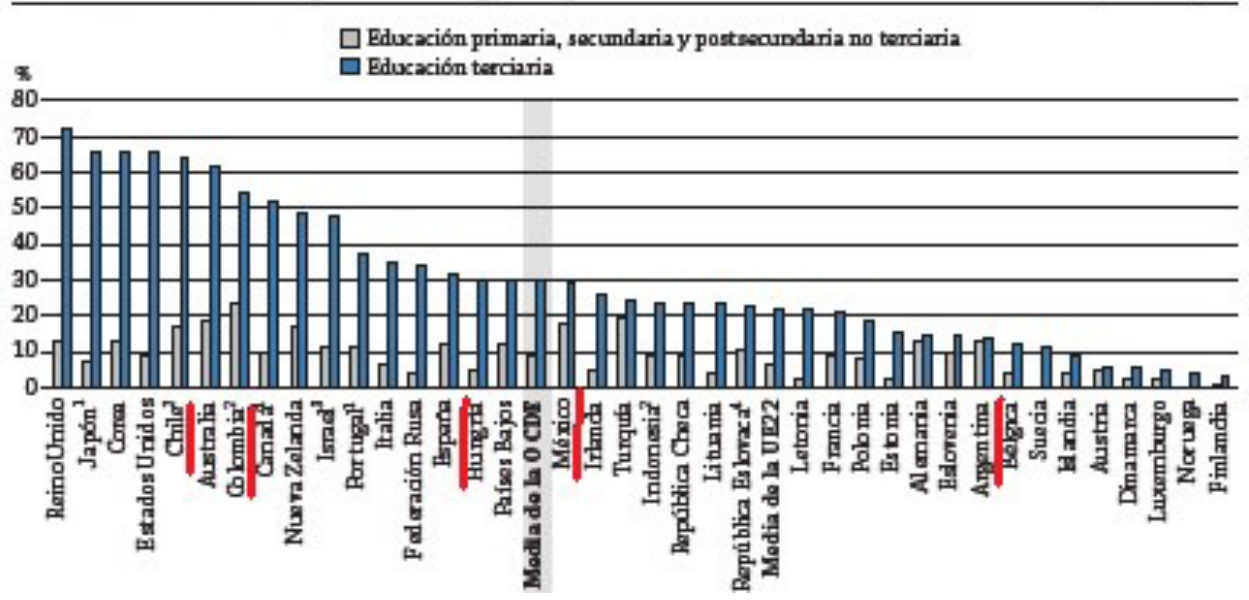

Ilustración 7. Fuente: OCDE. Panorama de la Educación 2017.

Hay una agenda planificada para la privatización de los recursos públicos en la que se incluye el paso previo del deterioro del servicio para justificar su privatización. El caso de la educación es quizá, uno de los más paradigmáticos: externalización de servicios, conciertos de financiación de centros privados con fondos públicos (que han ido incrementándose al tiempo que decrece la financiación pública para los centros públicos). Se han introducido las prácticas de los 
mercados dentro de la lógica de las universidades: se han aumentado las tasas, se han introducido las becas-préstamo y se ha incentivado la competencia entre universidades para recibir financiación en función de los resultados, al tiempo que en la "estrategia universidad 2015", en España, se ha priorizado la "transferencia del conocimiento" para que la universidad pública obtenga financiación privada a través de investigaciones vinculadas al mundo empresarial. Esto es, la universidad pública al servicio de los intereses privados de la industria.

\section{Educación. Porcentaje del Gasto Total de Gobierno. Datos}

\section{CEPAL}

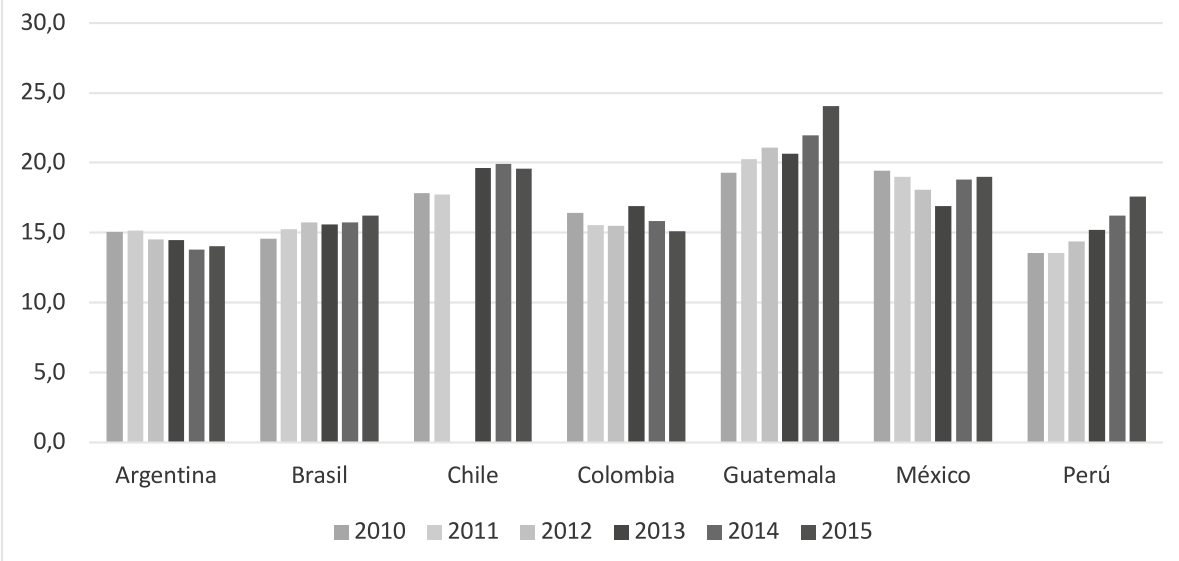

Ilustración 8. Elaboración propia a partir de datos de CEPALSTAT.

Gasto por alumno, nivel terciario (\% del PIB per cápita)

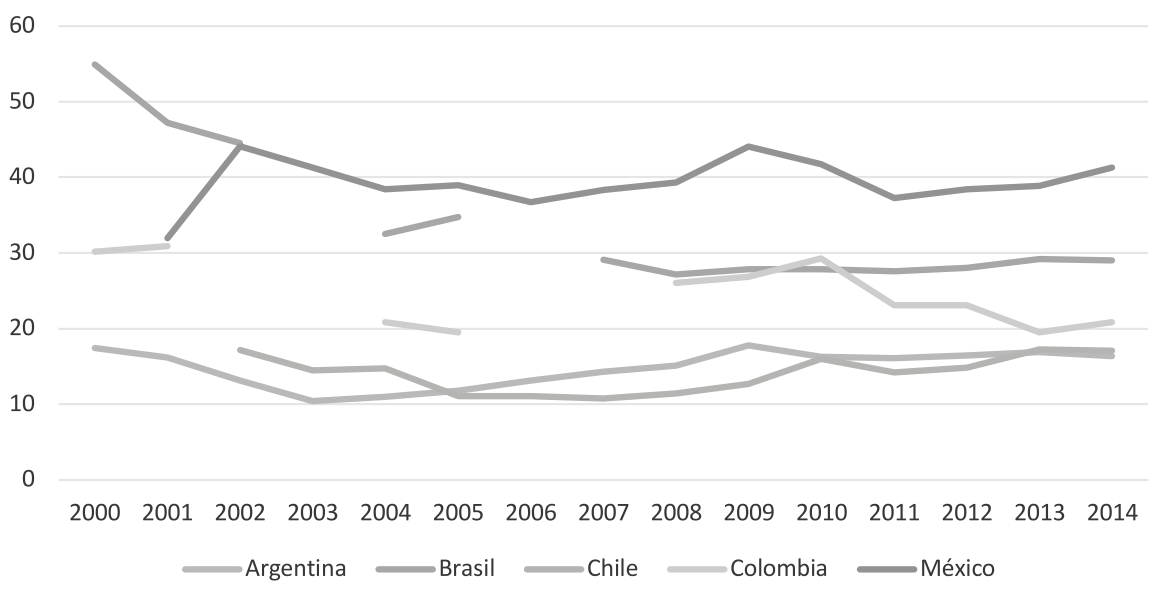

Ilustración 9. Elaboración propia a partir de datos del Banco Mundial. 
La Organización para la Cooperación y el Desarrollo Económicos (OCDE) en su informe de 2017 indicó los campos de estudio más populares en los que se matriculan los estudiantes de educación terciaria son ciencias empresariales, administración y derecho, mientras que los menos demandados son ciencias, tecnología, ingeniería y matemáticas. Aproximadamente, un $23 \%$ de los alumnos de nuevo ingreso en la educación terciaria elige estudiar ciencias empresariales, administración y derecho, frente al 16 \% que decide matricularse en ingeniería, construcción y producción industrial, y el $6 \%$ que escoge ciencias naturales, matemáticas y estadística. El informe de la OCDE indica que el campo de las tecnologías de la información y la comunicación (TIC) atrae a menos de un $5 \%$ de los alumnos de nuevo ingreso, lo que representa el menor porcentaje para un campo de estudio que, sin embargo, cuenta con la tasa de empleo media más alta en los países de la OCDE ya que llega a superar el $90 \%$ en cerca de un tercio de ellos.

Los resultados aparecen también confirmados por la base de datos de UNESCO: en el área iberoamericana las carreras que más alumnos atraen son ciencias sociales, economía, administración y derecho: según los países, se concentra en estas carreras entre un 25 y un $44 \%$ de las matrículas. Le siguen las áreas de ingeniería y construcción, salud y bienestar y educación. ${ }^{33}$

Pese a que recientemente muchos países de la OCDE han incentivado la formación de científicos, la tasa de empleo asociada a los graduados en campos como las ciencias naturales, estadística o matemáticas, corresponde más con las bajas perspectivas de empleo de los graduados en artes y humanidades que con las altas de los ingenieros y especialistas en TIC.

Continúa, según este informe, perdurando la diferencia entre mujeres y hombres al escoger su futura carrera profesional: en la profesión docente, más de cada diez profesores son mujeres y en ciencias e ingenierías, los hombres siguen superando a las mujeres.

\section{Gasto público social en educación respecto del} porcentaje del gasto público total

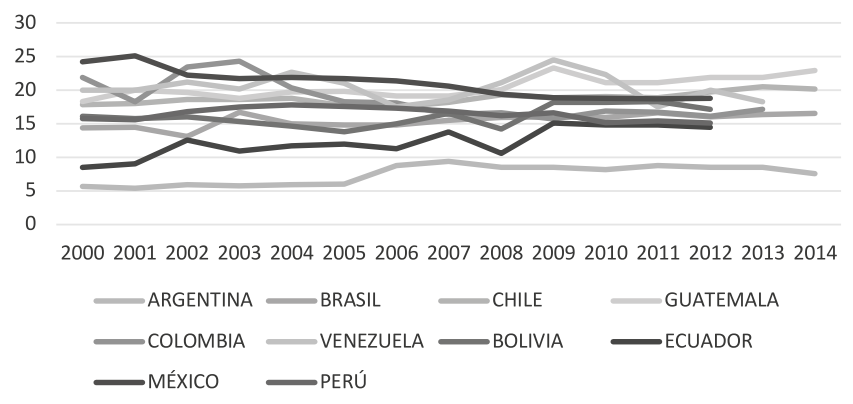

Ilustración 10. Elaboración propia a partir de datos del Banco Mundial.

33 José Joaquín Brunner, (Coord.). Educación Superior en Iberoamérica. Informe 2016 (Santiago de Chile: Centro Interuniversitario de Desarrollo (CINDA), 2016), 119. 
Desde 1990 hasta 2015, el número de estudiantes se multiplicó por 3,56 y la tasa bruta de matriculación en la educación superior pasó de un promedio ponderado de $20,41 \%$ en 1990 a un $54,35 \%$ en 2015 , con tres fases: un crecimiento moderado (1990-1995), un crecimiento acelerado (1995-2008) y un crecimiento lento (2009-2015). Los gobiernos, se dividieron entre aquellos con alto gasto y alta cobertura (Chile y Costa Rica); bajo gasto de gobierno y alta cobertura (Colombia y Brasil); bajo gasto de gobierno y baja cobertura (Perú, México, Panamá o Guatemala) y países con alto gasto de gobierno y baja cobertura (Ecuador, Bolivia, Paraguay o Nicaragua). ${ }^{34}$

Por tanto, podemos indicar que la desinversión, la falta de ayudas públicas, la externalización de servicios y el sometimiento de la universidad pública a las políticas neoliberales llevan el sistema público de educación superior al colapso. La tendencia es homogénea en todo el espacio iberoamericano, salvo honrosas excepciones.

\section{Hacia la construcción del Espacio Iberoamericano del Conocimiento (EIC)}

Si comparamos el resultado de las declaraciones de Bolonia con las de las cumbres iberoamericanas, observamos un indudable proceso de "boloñización" del espacio de educación superior latinoamericano. Imperan conceptos foráneos, procedimientos extraños a la idiosincrasia de las sociedades latinoamericanas, que toman como bueno lo foráneo solo por serlo. Pocas veces desde lo latinoamericano se toma la iniciativa y cuando se hace, languidece hasta desaparecer. La primera cumbre iberoamericana, la de Guadalajara, comenzó adelantándose en casi diez años a la creación del Espacio Europeo de Educación Superior y enunció, de forma pragmática y sin ambages, que el espacio del conocimiento era un mercado. En la declaración final, se afirmó la común voluntad de promover

Un mercado común del conocimiento como un espacio para el saber, las artes y la cultura, liberalizando los intercambios de materiales culturales, didácticos y educativos; facilitando el intercambio y la provisión de equipamiento científico y tecnológico $(\ldots)^{35}$

Pero, como indicábamos, las buenas pretensiones y la genuinamente innovadora idea de aglutinar tradiciones culturales, referencias y saberes, idiosincrasias e historias comunes, desaparecieron tan rápido como habían sido creadas. $\mathrm{Ni}$ tan siquiera la tentadora idea de comerciar con el conocimiento sirvió para sentar las bases de un espacio común. Las posteriores declaraciones de Madrid (1992), Bahía (1993), Cartagena (1994), Bariloche (1995) y las sucesivas de Viña

\footnotetext{
34 Emilio Rodríguez Ponce, "Financiamiento y gestión en las instituciones de educación superior en América Latina y El Caribe", en $E l$ papel estratégico de la educación superior en el desarrollo sostenible de América Latina y El Caribe, Coord. Pedro Henríquez Guajardo (Córdoba, Argentina: UNESCO-IESALC y UNC, 2018), p. 67.

35 Cumbres Iberoamericanas de Jefas $y$ Jefes de Estado y de Gobierno. En https://goo.gl/FByajF
} 
del Mar, Margarita y Oporto (1997) difuminarán la idea de creación de un espacio común de conocimiento y grandes y vacías ideas se apoderarán de las declaraciones finales.

Si las declaraciones de principios de los años noventa estuvieron marcadas por la visión de la educación como herramienta para combatir la miseria, empoderar la democracia en la región (Guadalajara, 1991); contribuir a un desarrollo personal que fuese más allá del mero beneficio económico y su consideración como "capital humano" (Cartagena de Indias, 1994); hacer la educación superior permeable a la entrada de grupos sociales desfavorecidos y convertirla en un motor en la lucha contra la pobreza y la marginación (San Carlos de Bariloche, 1995), las declaraciones de los años 2000 remarcaron la idea de la utilidad de la educación superior para formar mano de obra cualificada. En la Declaración de Lima (2001) se identificó la calidad educativa con la posibilidad de que la región se integrase en los nuevos escenarios socioeconómicos del nuevo milenio. El concepto de "calidad" estuvo ya presente en la mayor parte de las declaraciones, pero sin especificar claramente qué debía ser la calidad en cada uno de los contextos educativos latinoamericanos, o peor, asociando la calidad a la forma boloñesa de entenderla. De este modo, aunque la Declaración de San José (2004) estableció como indispensable la inversión en educación, aunque vinculó la investigación a los intereses económicos nacionales y puso, así, las bases del sometimiento del conocimiento a las necesidades empresariales. En este mismo sentido, debemos entender la alusión a los microcréditos y servicios de orientación profesional para estudiantes que se hizo en la Declaración de San Salvador (2008) y el sugerido vínculo entre educación superior y empresa enunciado en la Declaración de Mar del Plata (2010), o la necesidad de que las empresas monitorizasen los procesos formativos para desarrollar el "emprenderismo" y así crear puestos de trabajo, tal y como se declaró en Cádiz (2012). Empleo, productividad, competitividad, políticas educativas que se vinculen con el mundo del trabajo, alianza entre universidades, empresas y sociedad civil, fueron los procesos más remarcados en las cumbres de Panamá (2013), Veracruz (2014) y Cartagena (2016). ${ }^{36}$

La idea de un "Pacto Iberoamericano por la Educación", y, particularmente, el magnífico proyecto de creación de un Espacio Iberoamericano del Conocimiento (punto 13 de la declaración de Salamanca, 2005) "orientado a la necesaria transformación de la Educación Superior, y articulado en torno a la investigación, el desarrollo y la innovación" ha continuado siendo recordado en las posteriores cumbres, pero sin la determinación necesaria para ponerlo definitivamente en marcha. La creación de este Espacio Iberoamericano del Conocimiento (EIC), aún tuvo eco en la declaración de Mar del Plata (2010), como impulso (punto 16 de la declaración) en la tarea de "consolidar las redes y espacios del conocimiento a nivel subregional, regional e internacional que favorezcan la cooperación interuniversitaria y la movilidad académica". Este espacio, además, se ha inten-

36 Cumbres Iberoamericanas de Jefas y Jefes de Estado y de Gobierno. En https://goo.g1/FByajF 
tado complementar con la consolidación de un Espacio cultural iberoamericano (Declaraciones de Paraguay, 2011 y Cádiz, 2012), determinando en Veracruz 2014, la consolidación del Espacio Iberoamericano del Conocimiento, el Espacio Cultural Iberoamericano y el Espacio Iberoamericano de Cohesión Social, aunque, eso sí, con un orden jerárquico claramente definido y determinado. En la Declaración de Cartagena de 2016, se indicó en su punto 6 que se acordaba "Aprovechar las oportunidades que ofrece el espacio iberoamericano y profundizar los vínculos en las tres áreas identificadas como prioritarias -Comercio e Inversión, Servicios y Ciencia y Tecnología-, conforme a lo expresado en el Encuentro Empresarial Iberoamericano celebrado en Buenos Aires, el 25 y 26 de abril del corriente año". ${ }^{37}$ De momento, uno de los ejes centrales de actuación del Espacio Iberoamericano del Conocimiento ha sido la movilidad académica, que en la actualidad, cuenta con tres convocatorias ${ }^{38}$ :

- $\quad$ El Proyecto de Movilidad de Docentes Paulo Freire

- $\quad$ El Programa de Intercambio y Movilidad Académica (PIMA)

- El Programa Cumbre Pablo Neruda

Es fundamental, es necesario, es imprescindible, la recuperación de la universidad latinoamericana para que continúe desarrollando una capacidad crítica de las tradiciones culturales de las sociedades latinoamericanas, que rompa la dependencia con respecto a modelos foráneos y halle explicación al terrible problema de la injusticia estructural ${ }^{39}$.

\section{CONCLUSIÓN}

Es imprescindible adoptar perspectivas que prioricen las soluciones locales, regionales, nacionales y transregionales, sobre los problemas y soluciones globales. Lo global debe ser un referente, pero no el perpetuo modelo que sirva de panacea para la resolución de los problemas regionales. La creación de un Espacio Iberoamericano del Conocimiento no puede ser solo una intención, ni puede ser solo un bello pensamiento, sino una contundente acción transregional que identifique problemas propios e impulse soluciones contextualizadas que refuercen el papel de la Educación Superior pública en Iberoamerica: los proyectos y programas que originan este espacio son solo un tímido inicio, insuficiente y abandonado.

Esta investigación demuestra la necesidad de dotar de contenido, acción y recursos al Espacio Iberoamericano del Conocimiento. En este sentido, y contradiciendo el modelo neoliberal impuesto, la universidad pública debe recuperar el sentido de universalidad que la ha caracterizado desde su creación, para con-

37 XXV Cumbre Iberoamericana de Jefes de Estado y de Gobierno. Cartagena de Indias, 28 y 29 de octubre de 2016. En https://goo.gl/ GR5qf6

38 Centro de Altos Estudios Universitarios. En https://goo.gl/QnFcVV

39 Jorge Mario Rodríguez Martínez, "La Universidad Latinoamericana como recuperación y futuro", Revista Historia de la Educación Latinoamericana, vol.16 no. 22 (2014): 19-34. 
vertirse de nuevo en una herramienta de transformación social que priorice la creación de una conciencia crítica. En este sentido, los Estados nacionales deben garantizar una educación pública, gratuita y de calidad, atendiendo las necesidades del sistema productivo, pero no sometiendo a las instituciones educativas a sus designios e intereses. En este sentido, los Estados deben garantizar su desarrollo a partir de la extensión de la educación pública gratuita a todos los sectores de población, garantizando una formación de calidad y eludiendo el riesgo de la fuga de talentos a partir de ofertas laborales excelentes para aquellos estudiantes con capacidades excelentes.

La educación no puede ser vista como un gasto, sino como una inversión que ayude a progresar en el desarrollo de las sociedades iberoamericanas y aleje la amenaza de la exclusión social a importantes capas sociales que ahora mismo están excluidas o en importante riesgo de serlo. Para ello, el Espacio Iberoamericano del Conocimiento debe convertirse en un arma eficaz que al tiempo que homogeneice el espacio iberoamericano, según una cultura e idiosincrasia comunes y consensuadas, sepa respetar la inmensa diversidad que subyace en las sociedades multiétnicas y plurinacionales que conforman las sociedades iberoamericanas.

\section{FUENTES}

Centro de Altos Estudios Universitarios. En https://goo.gl/QnFcVV

Comunicado de Bergen. Conferencia Europea de Ministros de Educación Superior (Berlín:2005). En https://goo.gl/WhMncM

Comunicado de Berlín. Conferencia Europea de Ministros de Educación Superior (Berlín:2003). En http:// www.eees.es/pdf/Berlin_ES.pdf

Constantinescu, Mara. “La paradoja inclusiva. Efectos a corto y largo plazo de las políticas públicas para la educación superior en Colombia" (tesis de Máster en Latin American Studies, Leiden University, julio, 2018), 43

Cumbres Iberoamericanas de Jefas y Jefes de Estado y de Gobierno. En https://goo.gl/FByajF

Cumbres Iberoamericanas de Jefas y Jefes de Estado y de Gobierno. En https://goo.gl/FByajF

Didou Aupetit, Sylvie y Etienne Gérard. Fuga de cerebros, movilidad académica, redes científicas, México: Centro de Investigaciones y de Estudios Avanzados del Instituto Politécnico Nacional, 2009.

El Confidencial. Trump incendia Silicon Valley: su plan antiinmigración afecta al 20\% de empleados. En https://goo.gl/UPLGUk

El Observatorio de la Universidad Colombiana, Universidades "sin ánimo de lucro" ganaron 464.000 millones de pesos en 2009 (Ministerio de Educación de Colombia, 2011), en https://goo.gl/ JnWbJ9

Gentili, Pablo, "Desigualdad e inclusión en las universidades latinoamericanas". En Contrapuntos, Diario El País, 31/07/2016 https://goo.gl/VGYucB

OCDE/CAF/CEPAL Perspectivas económicas de América Latina 2018: Repensando las instituciones para el desarrollo, Éditions OCDE, París, 2018.

OCDE/CEPAL/CAF Perspectivas económicas de América Latina 2017: Juventud, competencias y emprendimiento, OECD Publishing, Paris: 2016, http://dx.doi.org/10.1787/leo-2017-es

OECD, Hanushek and Woessmann. Universal Basic Skills: What Countries Stand to Gain, http://dx.doi. org/10.1787/9789264234833 En OCDE. Fundación Santillana, Competencias en Iberoamérica: Análisis de PISA 2015. Fundación Santillana, 2018. 


\section{REFERENCIAS}

Albornoz, Orlando, "La empleabilidad: las universidades, los profesionales universitarios y el comportamiento del mercado laboral", en El papel estratégico de la educación superior en el desarrollo sostenible de América Latina y El Caribe, Coord. Pedro Henríquez Guajardo (Córdoba, Argentina: UNESCO-IESALC y UNC, 2018), 134.

Armenteros, Juan Hernández y José Antonio Pérez García, CRUE, Universidades Españolas, La Universidad Española en Cifras. Valencia: CRUE, 2017.

Arocena, Rodrigo. "Las reformas de la educación superior y los problemas del desarrollo en América Latina". Educ. Soc., Campinas, vol. 25, n. 88 (2004): 915-936.

Brunner, José Joaquín, (Coord.). Educación Superior en Iberoamérica. Informe 2016 (Santiago de Chile: Centro Interuniversitario de Desarrollo (CINDA), 2016), 159.

Brunner, José Joaquín (Coord.). Educación Superior en Iberoamérica. Informe 2016 (Santiago de Chile: RIL Editores, 2016), 17.

Brunner, José Joaquín (Coord.). Educación Superior en Iberoamérica. Informe 2016, (Santiago de Chile: Centro Interuniversitario de Desarrollo (CINDA), 2016), 194.

Cuño Bonito, Justo. Reforma y Contrarreforma de la Enseñanza Primaria durante la II República Española y el Ascenso del Fascismo (1932-1943). Revista Historia de la Educación Latinoamericana vol. 15 no. 21 (2014): 89-106. https://doi.org/10.19053/01227238.2468.

Escalante Semerena, Roberto. "Lo público y lo privado en la educación superior en América Latina". En https://goo.gl/xkXCcJ

Fernández Lamarra, Norberto. "Hacia la convergencia de los sistemas de educación superior en América Latina". Revista Iberoamericana de Educación, no. 34 (2004): 39-71.

García Guadilla, Carmen. "Lista de Universidades de América Latina desde su fundación". En https:// goo.gl/1sTc57

Gramsci, Antonio. La Política y el Estado Moderno. México: Premiá, 1978.

Locke, John. Segundo Tratado sobre el Gobierno Civil: un ensayo acerca del verdadero origen, alcance y fin del gobierno civil, Madrid: Tecnos, 2006.

Molina Bravo, José. “Educación Pública, Autonomía Universitaria y Cambio Político: Notas para el Análisis Del Movimiento Universitario en Chile, 2011". Revista Historia de la Educación Latinoamericana vol. 15 no. 21 (2014): 263-82. https://doi.org/10.19053/01227238.2473.

Pérez García, Francisco y Lorenzo Serrano Martínez (Dirs.), Universidad, Universitarios y Productividad en España. Bilbao: Fundación BBVA, 2012.

Poo del Castillo, Ana Isabel. "La empresa McDonald's: un elemento positivo en el proceso globalizador" (Tesis profesional, Licenciatura en Relaciones Internacionales. Universidad de las Américas, Puebla, 2006), cap. III, 15.

Recio Andreu, Albert. "Educación y capitalismo en el análisis 'radical' de S. Bowles y H. Gintis". Revista de Economía Crítica, n¹8, segundo semestre (2014): 215-217.

Rodríguez Martínez, Jorge Mario, "La Universidad Latinoamericana como recuperación y futuro", Revista Historia de la Educación Latinoamericana. Vol. 16 no. 22 (2014): 19-34.

Rodríguez Ponce, Emilio, "Financiamiento y gestión en las instituciones de educación superior en América Latina y El Caribe", en El papel estratégico de la educación superior en el desarrollo sostenible de América Latina y El Caribe, Coord. Pedro Henríquez Guajardo (Córdoba, Argentina: UNESCO-IESALC y UNC, 2018), p. 67.

Salas, Manuel. "Invertir en Universidad, una apuesta rentable", El País, 1 julio 2013. En https://goo.gl/ QPj9XB Consultado el 5 de marzo de 2017.

Sánchez Caballero, Daniel. "Relato de una Universidad en crisis: menos financiación pública, más gasto privado y más lejos de Europa" (eldiario.es, 2018), en https://goo.gl/TehVye

Soto Arango Diana Elvira, José Pascual Mora, José Rubens Lima Jardilino, “Formación de docentes y modelo pedagógico en la Universidad Pedagógica y Tecnológica de Colombia", Revista Historia de la Educación Latinoamericana, vol.19 no. 29 (2017): 35 - 66.

Soto Arango, Diana Elvira y Araceli Forero Romero, "La Universidad Latinoamericana y del Caribe en los desafíos del siglo XIX", Revista Historia de la Educación Latinoamericana. Vol. 18 no. 26 (2016): 279-309. 
UNESCO destaca escasez de ingenieros como amenaza al desarrollo - 2010. En https://goo.gl/ aG89wk

Van Damme, Dirk. El crecimiento de la movilidad estudiantil internacional está cayendo. N. 93 (2018): 9-11.

XXIV Cumbre Iberoamericana de Jefes de Estado y de Gobierno. Declaración de Veracruz. En https:// goo.gl/SkSVaR

XXV Cumbre Iberoamericana de Jefes de Estado y de Gobierno. Cartagena de Indias, 28 y 29 de octubre de 2016. En https://goo.gl/GR5qf6

Cómo citar:

Cuño Bonito, Justo. “El Espacio Iberoamericano del Conocimiento en la perspectiva de transformación de la Universidad en una Microversidad" Revista Historia de la Educación Latinoamericana. Vol. 21 No. 32 (2019): 35-58

https://doi.org/10.19053/01227238.9059

(ब) $\mathbb{\Theta \Theta}$ Esta obra está bajo una licencia Creative Commons.

Reconocimiento-No Comercial-Sin Obra Derivada 2.5 Colombia. 